REVISTA X, Curitiba, volume 14, n.6,p. 87-106, 2019.

\title{
UMA PROPOSTA DIDÁTICA DE ENSINO DE INGLÊS COMO LÍNGUA ESTRANGEIRA PARA PROMOÇÃO DA JUSTIÇA SOCIAL
}

A Didactic Proposal for Teaching English as a Foreign Language for Promoting Social Justice

\author{
Míriam Rabelo GONTIJO (CEFET-MG) ${ }^{1}$
}

\begin{abstract}
RESUMO: Este artigo busca discutir o papel da escola e dos educadores frente a um novo comportamento social dos aprendizes possibilitado pela globalização, bem como relatar a experiência pessoal da autora deste texto, ao realizar uma atividade com seus alunos do curso de Licenciatura em Letras da Universidade Estadual de Minas Gerais - UEMG no segundo semestre de 2018. A atividade propunha que os alunos criassem livros de literatura infantil para serem doados para as escolas públicas. $\mathrm{O}$ artigo traz o detalhamento da atividade desenvolvida, bem como as impressões registradas ao longo do processo quanto ao cumprimento da proposta de se trabalhar sob o viés da pedagogia crítica (PENNYCOOK, 1994), na busca pelo desenvolvimento dos multiletramentos (THE NEW LONDON GROUP, 1996) visando a um ensino transformador (KALANTZIS, 2006; COPE; KALANTZIS, 2008). A proposta resultou na confecção de 29 livros infantis cuidadosamente elaborados para serem doados às escolas públicas da cidade. As obras dividiram-se em 10 sub-temas, a partir da temática diversidade. Os estudantes mostraram-se engajados e motivados, o que resultou em um trabalho de grande relevância para a comunidade escolar local.
\end{abstract}

PALAVRAS-CHAVE: Ensino Transformador; Justiça Social; Literatura Infantil; Pedagogia Crítica.

\begin{abstract}
This article aims to discuss the role of the school and educators in general who have been dealing with a new social behavior of learners, brought by globalization, as well as to report the personal experience of this text's author, based on a pedagogical practice conducted in partnership with her students from Universidade do Estado de Minas Gerais - UEMG, during the second semester of 2018. The activity proposed the creation of children's literature books to be donated to public schools. The article details the development of the activity, as well as the impressions recorded during its process, regarding the fulfillment of the proposal of working guided by a critical pedagogy (PENNYCOOK, 1994), seeking to develop the multiliteracies (THE NEW LONDON GROUP, 1996) in view of a transformative teaching (KALANTZIS, 2006; COPE; KALANTZIS, 2008). The proposal resulted in 29 carefully designed children's books to be donated to the city's public schools. The general theme was divided into 10 subthemes, under the subject diversity. Students were engaged and motivated, which resulted in a work of great relevance to the local school community.
\end{abstract}

\footnotetext{
Doutoranda no Programa de Pós-Graduação em Estudos de Linguagens pelo CEFET-MG. miriamrgontijo@hotmail.com
} 
KEYWORDS: Children's Literature; Critical Pedagogy; Social Justice; Transformative Teaching.

\section{INTRODUÇÃO}

A globalização, impulsionada pelos avanços tecnológicos das últimas décadas, tem unido pessoas ao redor do mundo, ao mesmo tempo em que reforça suas diferenças. Com isso, praticamente todas as áreas da vida dos indivíduos da sociedade moderna têm sido modificadas, alterando, como consequência, suas atitudes e comportamentos. Nesse contexto de mudanças tecnológicas e sociais profundas, é necessário repensar o papel que a escola e educadores assumem na educação contemporânea (MATTOS, 2016).

Mattos (2012) aponta que o ensino de inglês em países como o Brasil foi fortemente influenciado pela globalização. Nessa conjuntura, a autora (2014) pontua que o papel da Língua Inglesa (doravante LI) como segunda língua (doravante L2) tem sido amplamente debatido, por ter se tornado não apenas um instrumento que permite a comunicação entre diferentes culturas, mas também uma ferramenta de poder e dominação social.

Há, portanto, um desafio sendo lançado não somente aos professores de línguas das escolas brasileiras, como também aos profissionais da educação em geral: repensar formas de auxiliar os alunos a ultrapassar a posição que muitos ainda ocupam, de aprendizes passivos, que dispensam pouca energia para o desenvolvimento de sua própria aprendizagem, no intuito de contribuir para que eles se tornem aprendizes mais ativos, dispostos a empregar maior energia para aprenderem. Nessa conjuntura, uma mudança na forma de compreender e dinamizar o processo de ensino e aprendizagem pode ser de grande valia para que esses aprendentes se tornem cidadãos melhor preparados para atuarem no meio em que vivem, alterando-o em favor de uma sociedade mais justa.

Rabin (2009, p. 189) aponta que a "a chave para se tornar um promotor ativo da justiça [social] é perceber que cada pessoa é enfraquecida pela injustiça social"2. A autora advoga que, ao defender a justiça social, não o fazemos em favor dos outros, mas em nosso próprio benefício e da humanidade, que é diversa. Rabin pontua ainda que para que as pessoas não se limitem à sua zona de conforto, é preciso que promovam a diversidade em sua vida cotidiana ou se conformem em viver na mesmice de seu

\footnotetext{
${ }^{2}$ The key to becoming an active advocate for justice is realizing that every single person is diminished by social injustice.
} 
pequeno espaço familiar. Desse modo, considerando que a educação visa formar um cidadão mais autônomo e, ao mesmo tempo, mais consciente acerca de suas responsabilidades para o bem comum, é importante que a escola reforce a ideia de uma sociedade diversa e, ao mesmo tempo, igualitária e que ajude na formação de cidadãos conscientes quanto ao exercício da cidadania.

Uma abordagem que se ancora nesses pressupostos é a pedagogia crítica. Segundo Pennycook (1994) essa abordagem busca promover momentos de reflexão objetivando, dentre outros pontos, a formação de cidadãos mais críticos, éticos e politizados no intuito de promover uma educação em favor de uma mudança social para o benefício da escola e da comunidade.

Ainda acerca do desafio em que se encontram os docentes na atualidade, Prensky (2011, p. 1) salienta que grande parte dos aprendizes que estão nas escolas hoje são "nativos digitais". Ele explica que os "nativos digitais são 'falantes nativos' da linguagem digital dos computadores, vídeo games e internet”; portanto, são aprendizes que têm a informação ao alcance de suas mãos, o que pode contribuir para um processo de aprendizagem mais autônomo, pautado por suas próprias necessidades.

Desse modo, considerando o perfil do estudante na atualidade e tendo em vista as possibilidades embutidas na pedagogia crítica, que incluem o desenvolvimento dos multiletramentos (THE NEW LONDON GROUP, 1996) para uma formação integral do estudante, é importante considerar as vivências, identidades e crenças dos alunos, bem como seus conhecimentos já adquiridos. Moraes Bezerra e Santos (2018, p. 6) apontam que é de grande relevância colaborar para que os aprendizes "se sintam usuários legitimados desse idioma [inglês] para fazer sentido do mundo social e para trazer suas questões e reflexões, ou seja, para que a língua esteja a serviço de suas necessidades de interação e de construção de sentidos". Nesse contexto, tem-se que quando a língua inglesa é ensinada visando a negociação de sentido, a aprendizagem se torna mais significativa para o aprendente.

No segundo semestre de 2018, ao ser efetivada no cargo de professora de Língua Inglesa em uma escola do Estado, a professora-autora deste artigo buscou desenvolver um trabalho com alunos do sexto ano do ensino fundamental por meio da literatura infantil. Tal proposta se deu por acreditar que o uso de textos literários em sala de aula de língua inglesa oferece ao estudante diversas possibilidades que podem não apenas aumentar a sua competência linguística, mas também ampliar o seu conhecimento de mundo (YAMAKAWA, 2013). No entanto, na escola onde trabalhava havia apenas três 
livros infantis em língua inglesa que além de bem velhos e em mau estado de conservação, eram demasiadamente longos para a faixa etária com a qual se propunha trabalhar.

Ao mesmo tempo, na universidade, a professora discutia com seus alunos do curso de Licenciatura em Letras textos sobre a pedagogia crítica (GIROUX, 1991; PENNYCOOK, 1994; FREIRE, 2004), sobre o desenvolvimento dos multiletramentos no ensino de L2 (THE NEW LONDON GROUP, 1996) e sobre o ensino transformador de inglês como língua estrangeira (KALANTZIS, 2006; COPE; KALANTZIS, 2008). Ao perceber que a escola regular não possuía os livros necessários para seu trabalho, a docente sugeriu que os universitários os confeccionassem e posteriormente os doassem àquela escola estadual, traçando, com isso, uma ponte entre universidade e comunidade.

Rabin (2009, p. 189) salienta que "toda criança carrega uma perigosa bagagem psicológica por crescer com uma noção sancionada pelo governo de que alguns seres humanos valem menos a pena que outros". Diante disso, este artigo objetiva discutir o papel da escola e dos educadores frente a um novo comportamento social oriundo de uma comunicação em rede instantânea, que conecta povos de todas as etnias, cores e credos ao redor do mundo por meio da apresentação de uma proposta didática aplicada a alunos do curso de Licenciatura em Letras.

No novo cenário que se desvela, é importante discutir sobre um ensino de inglês embasado em uma pedagogia crítica que visa à justiça social ao possibilitar um ensino crítico e reflexivo (FREIRE, 2012). O crítico, neste contexto, é compreendido como um estado de percepção do indivíduo em relação ao ambiente que ele vivencia. Trata-se de um constante exercício de ruptura com verdades engendradas constantes no discurso da sociedade pós-moderna (MONTE-MÓR, 2013). Desse modo, é importante que, ao ensinar, o professor considere a integração entre pessoas, permitindo uma geração de aprendizes mais preparada para lidar com o outro, reconhecendo as suas particularidades.

\section{ENSINO DE L2 POR MEIO DE UMA PEDAgOGIA CRÍTICA PARA A JUSTIÇA SOCIAL}

A sociedade mostra-se desigual. Em diversos campos da interação humana há relações de opressão, o que desumaniza as relações sociais (SANTOS, 2018). Nesse contexto, Freire (2004) propõe uma ideia de empoderamento por meio de uma pedagogia libertadora, que possibilite ao oprimido romper com o seu status e adquirir 
uma nova estrutura de aprendizagem que lhe permita buscar novos conhecimentos e ter uma participação social mais relevante.

Freire (2004) defende uma prática de ensino que se volte para a contestação dos sistemas de opressão, a pedagogia crítica. Essa pedagogia em favor da justiça social torna-se relevante para a promoção de uma sociedade mais humana, ao instigar um pensamento crítico sobre a sociedade e sobre o papel de cada aprendiz no contexto social onde atua.

Pennycook (1994) afirma que a pedagogia crítica percebe a escola como um local em que formas culturais, sociais e ideológicas estão constantemente em luta. $\mathrm{O}$ autor afirma que há um questionamento sobre como construir uma teoria em acordo com práticas educativas que possam desenvolver modos de ensinar que ofereçam maiores possibilidades para que as minorias tenham melhores chances de êxito nos modos definidos pela educação. Nesse contexto, é importante investir na formação de docentes para que práticas pedagógicas significativas sejam criadas em consonância com as necessidades dos alunos, levando em conta toda a complexidade envolvida no processo de ensino e aprendizagem.

Zeichner (2010) propõe uma abordagem para a educação de docentes, que ele nomeia Social Justice Teacher Education. Tal abordagem objetiva preparar docentes para ensinar de forma a contribuir para a diminuição de desigualdades e injustiças que existem no mundo, tanto no sistema educacional, como na sociedade como um todo. Ela salienta que o ato de ensinar visando à justiça social tem como foco ajudar a promover uma mudança social em larga escala, nos aspectos sociais, políticos e nas esferas educacionais da sociedade.

Para explanar a relação entre justiça social e educação, Freire (2004) argumenta que os sistemas de opressão são repassados de geração em geração. Na visão do autor, historicamente percebe-se, de um lado, os beneficiados, que são os que detêm o poder e têm influência no mercado financeiro, considerados os opressores, e, do outro, os marginalizados, pessoas oprimidas, mas que nem sempre têm consciência de sua opressão.

Para que haja equidade, é necessário um processo de libertação que busque romper com o imaginário de inferioridade dos oprimidos, o que seria possível apenas por uma ação coletiva em que estes reconhecessem o sistema de opressão. Nesse contexto, o fator principal para que haja tal reconhecimento é os marginalizados serem levados a repensar sua realidade, ou seja, na visão de Freire, a libertação se dá por meio 
da conscientização dos indivíduos, o que pode ocorrer por meio de uma educação reflexiva. Nesse aspecto, o autor $(2012$, p. 207) pontua que "é preciso, absolutamente preciso, que o saber de minorias dominantes não proíba, não asfixie, não castre o crescer das imensas maiorias dominadas". Trata-se, portanto, de permitir o ser crítico dentro das instituições para que sua atuação fora das instituições seja responsável e cidadã.

Para isso, educadores precisam repensar o ensino visando uma formação transformadora. Adams (2016) pontua que as escolhas pedagógicas dos educadores da justiça social são tão importantes quanto o conteúdo que ensinam, de forma que $o$ quê os aprendizes aprendem deve ser congruente com a forma como estão aprendendo.

Kalantzis (2006) explicita que uma educação transformadora modifica as dimensões arquitetônica, sociocultural, discursiva, pedagógica, intersubjetiva, moral e de propriedade relacionadas às práticas pedagógicas. Assim, a aprendizagem, antes entendida como um pacote entregue ao aluno dentro de uma sala de aula, passa a ser compreendida como um processo que ocorre dentro e fora dos limites institucionais e perduram por toda a vida.

Segundo a autora, nesse novo desenho educacional, o design da aula não é mais ditado pelo professor, mas construído com os aprendizes, que passam a ser codesigners. A aprendizagem, nessa perspectiva, ocorre de forma colaborativa, permeada por relações múltiplas que consideram o pluralismo de ideias em uma relação horizontal entre os participantes do processo, a quem é permitido negociar, navegar, mudar, criar e inovar.

O ensino transformador é, portanto, aquele capaz de dar ferramentas para que o indivíduo possa pensar e agir criticamente para a transformação do seu meio social, questionando e desafiando o pensamento hegemônico quando este objetiva calar vozes. É o ensino que educa pessoas em vez de doutriná-las, preparando-as para o exercício da cidadania, inclusão social e para a negociação de identidade, poder e capital.

Para que as práticas pedagógicas sejam transformadoras e voltadas para a justiça social, conforme sugerem Freire (2004) e Zeichner (2010), há de se considerar o desenvolvimento do letramento crítico. Por meio dele os alunos são instigados a lerem além das linhas de textos verbais. Na perspectiva do letramento crítico os indivíduos são estimulados a fazerem, de forma consciente, a leitura do mundo onde vivem, da cidade onde moram, do bairro onde habitam, para que, ao melhor compreender o seu entorno, possam atuar em favor de uma sociedade mais justa e mais humanizada. 
Lankshear e Knobel (1998, p. 8) percebem o letramento crítico como um “compromisso discursivo, uma forma de vida, um jeito de ser no mundo". Nessa mesma linha, Santos (2018) compreende que ser crítico tem a ver com a postura adotada pelo indivíduo. Em sua concepção, trata-se da visão dos sujeitos acerca do mundo a seu redor e da forma como eles reagem a estímulos e vivências humanas em toda a sua complexidade. Desse modo, levar os alunos a pensar criticamente e a usar textos e discursos para construir e negociar identidades, poder e capital faz parte do desenvolvimento do letramento crítico.

Desse modo, para o ensino de inglês como língua estrangeira, há de se pensar em práticas pedagógicas que levem os alunos a refletir sobre o uso da língua considerando, além dos aspectos linguísticos, o enfoque social. Brydon (2009, p. 7) aponta a necessidade de se "determinar que tipos de pedagogias e currículos são necessários para educar cidadãos sobre globalização, cidadania e cultura".

As práticas visando ao letramento crítico dentro da disciplina de LI devem fomentar a busca pelo conhecer global para compreender as demandas locais, no intuito de, por meio de interações humanas, agir localmente em favor de mudanças. Sobre isso, Van Lier (2000) propõe que a aprendizagem não é simplesmente sobre transferência de significados e conteúdos para dentro da cabeça dos aprendizes; trata-se, na visão do autor, de lidar com o mundo real e com seus significados. Assim, para ensinar é preciso olhar para o aprendiz e seu ambiente de uma forma ecológica, e não para os conteúdos que ele pode carregar ou não consigo.

Chiarini (2001) aponta que a sociedade contemporânea, em decorrência do processo de globalização, é híbrida, além de plural e integrada, ao mesmo tempo em que é marcada por reivindicações locais, que não podem ser desvalorizadas.

Visando contribuir com as reflexões aqui expostas, apresento a seguir uma prática pedagógica realizada em 2018 que objetivou envolver alunos de Letras em uma “discussão para ação" no ensino de inglês como língua estrangeira, sob o viés da pedagogia crítica.

\section{PROPOSTA DE ATIVIDADE VISANDO AO ENSINO DE LI PARA A JUSTIÇA SOCIAL}

Diversos são os desafios encontrados na complexidade de um ambiente escolar, em especial quando se trata de uma escola pública. A atividade a ser descrita teve início em outubro de 2018, quando, ao ser aprovada em um concurso da Secretaria Estadual de 
Educação, passei a vivenciar as particularidades do ensino público após passar grande parte de minha carreira em escolas particulares e cursos de idiomas. A escola estadual para onde fui designada situa-se no município de Divinópolis e oferece ensino integral, fundamental I e II e ensino médio a 497 alunos (BRASIL, 2018).

Ao conhecer a turma de sexto ano, quase chegando ao final do período letivo, pensei em trabalharmos juntos com a leitura de um livro infantil. Meu objetivo com essa atividade era conhecer melhor a turma, o seu conhecimento linguístico e perceber seus gostos e aspectos referentes ao seu processo de aprendizagem. No entanto, havia apenas 3 livros bastante velhos e pouco atraentes para se trabalhar com os alunos da educação básica de modo geral, e em especial com os aprendizes do sexto ano, com idade entre 11 e 13 anos. Para conhecer melhor a realidade das bibliotecas das escolas públicas, visitei outras 5 escolas estaduais da cidade e percebi que a defasagem de livros em inglês é comum a todas elas.

Concomitantemente, eu lecionava no curso de Letras de uma universidade pública da cidade e buscava, naquele semestre, abrir discussões acerca da relevância da pedagogia crítica (GIROUX, 1991; PENNYCOOK, 1994; FREIRE, 2004), do desenvolvimento dos multiletramentos no ensino de L2 (THE NEW LONDON GROUP, 1996) e do ensino transformador de inglês como língua estrangeira (KALANTZIS, 2006; COPE; KALANTZIS, 2008) nas escolas regulares. Surgiu, então, a ideia de envolver meus alunos do curso de Licenciatura em Letras em um projeto de elaboração de livros infantis e infanto-juvenis para serem doados para as escolas públicas da cidade, em especial para aquela em que eu trabalhava.

\section{ORGANIZAÇÃO DO PROJETO}

Conforme apresentado no plano de aula (APÊNDICE 1), no mês de outubro de 2018, os alunos do $2^{\circ}, 4^{\circ}$ e $6^{\circ}$ períodos do curso de Licenciatura em Letras haviam tido a oportunidade de discutir sobre as possibilidades da pedagogia crítica e do letramento crítico visando a um ensino transformador por meio de textos amplamente debatidos em sala, cujos autores foram citados anteriormente. Em uma das turmas, especificamente na do $6^{\circ}$ período, os alunos já iniciavam, naquele momento, seu estágio supervisionado em escolas públicas, e a proposta do semestre era que as aulas fossem ministradas em uma perspectiva crítica de ensino. Desse modo, grande parte dos alunos já discutia ideias e propostas que pudessem ser aplicadas durante o estágio. 
Em outubro, após perceber a defasagem nas bibliotecas das escolas públicas, reuni os alunos do curso de Letras para propor o projeto que substituiria a sua prova final. Em duplas ou trios, os discentes deveriam criar livros para serem doados para escolas públicas. Ao debater com a turma sobre quais seriam os temas das histórias, os alunos sugeriram escrever sobre diversidade, por ser uma temática que permitiria criar textos que pudessem ser trabalhados em sala de aula visando não somente ensinar gramática e vocabulário, mas expandir as discussões em busca de um ensino transformador e libertador, conforme sugere Kalantzis (2006). Dessa forma, os professores da rede pública teriam a oportunidade de fomentar a leitura em inglês e discutir o conteúdo dos livros em uma perspectiva crítica, conforme sugerem Lankshear e Knobel (1998), Freire (2004), Mattos (2011), Monte-Mór (2013) e Santos (2018).

A escolha pela temática diversidade vai ainda ao encontro das ideias de Pennycook (1994, p. 297) quando ele pondera que:

a pedagogia crítica precisa desenvolver modos de ensinar que ofereçam maiores possibilidades para pessoas de cor, minorias étnicas, estudantes da classe trabalhadora, mulheres, homossexuais e lésbicas, e outros, não só para que eles possam ter uma melhor chance de "sucesso" nos modos tradicionalmente definidos pela educação mas também para que estas definições possam ser mudadas tanto dentro quanto fora da escola.

$\mathrm{Na}$ primeira aula do projeto para a apresentação do gênero a ser trabalhado, promovi um momento de contação de história utilizando o livro The Lion Who Wouldn't Try, dos autores André Kieswetter, Liza Esterhuyse, Nick Mulgrew e Tarryn-Anne Anderson. Na sequência, mostrei diversos livros infantis à turma e deixei que eles percebessem as características do gênero e, dentre eles, quais aspectos eram obrigatórios e quais eram opcionais em um livro. Foi feito um brainstorming para fomentar a discussão sobre as percepções quanto à caracterização do gênero.

Os livros foram criados parcialmente em sala de aula, durante as aulas de inglês. Nesses momentos, os alunos puderam selecionar o subtema, criar suas personagens e fazer o esboço de seus textos. Além dessas aulas, foram reservados dois encontros para orientação grupo a grupo, quando os alunos puderam sanar suas dúvidas quanto à escrita textual. Para mais, coloquei-me à disposição para auxiliar os alunos com relação às escolhas linguísticas via aplicativo de mensagens e $e$-mail. Houve troca de mensagens frequentemente entre os envolvidos no projeto durante todo o tempo de elaboração do material, o que ilustra a ideia de Prensky (2011) quando ele cita que a informação está 
na palma das mãos e que as novas tecnologias contribuem para uma aprendizagem mais autônoma.

O layout da capa do livro, bem como as ilustrações, foi definido pelos grupos, sem minha interferência. Durante os encontros, alguns alunos relataram estar recebendo auxílio de familiares e amigos para as ilustrações. Percebi, desse modo, grande envolvimento e engajamento para o trabalho, que contou com esforços conjuntos de todo o grupo e de outras pessoas em seu entorno. A impressão dos trabalhos também foi de responsabilidade de cada grupo.

\section{PERCEPÇÕES SOBRE OS RESULTADOS ALCANÇADOS}

Uma das principais percepções que tive no decorrer do projeto foi a da dificuldade dos alunos em escreverem um livro para um público bastante jovem, considerando que aquele material deveria possibilitar discussões relevantes, mas de forma suave, que agradasse ao público-alvo. O processo de elaboração do material ocorreu de forma colaborativa, conforme sugerido por Kalantzis (2006) em que, juntos, os temas, personagens e roteiros foram definidos. O pluralismo de ideias entre os participantes do processo foi considerado em uma relação horizontal. O relato de umas alunas participantes da atividade ilustra essa questão:

(...) um momento significativo da experiência para mim foi quando paramos para definir as características físicas das personagens principais do livro e minha amiga sugeriu que elas fossem negras. Assim que ela disse passou pela minha cabeça que até o momento eu não tinha nem considerado aquilo enquanto eu escrevia. E eu percebi que talvez, inconscientemente eu até rejeitasse a ideia, então foi um momento de reflexão em que eu me perguntei porque eu não pensava em me representar nos meus escritos e apenas seguia o padrão ao descrever as personagens. Isso foi importante para mudar um pensamento que estava ali mas ao qual eu não dava muita atenção.

Na penúltima aula do semestre, os alunos apresentaram seus livros finalizados e entregaram a primeira versão impressa, exibindo, ali, um "sentimento de orgulho", como alguns definiram, por sentirem-se parte de um projeto de grande relevância. Ao criar aqueles livros, os alunos estavam disponibilizando, gratuitamente, possibilidades de se trabalhar sob o viés da pedagogia crítica, conforme Pennycook (1994) sugere que seja feito quando ele menciona a necessidade de se repensar as práticas pedagógicas. Por meio desse projeto, minorias puderam ser representadas nos livros. 
No total, foram confeccionados 29 livros. Os alunos selecionaram 9 diferentes subtemas a partir da temática diversidade. Os subtemas selecionados, bem como os títulos das obras, estão expostos no Quadro 1:

Quadro 1 - Tema, subtemas quantidades e títulos das obras

\begin{tabular}{|c|c|c|c|}
\hline TEMA & SUBTEMA & QUANTIDADE & TÍTULOS \\
\hline \multirow{9}{*}{ Diversidade } & Novos arranjos familiares & 2 & $\begin{array}{l}\text { Agnes in: a family is made of } \\
\text { love; A colorful family }\end{array}$ \\
\hline & Gêneros & 2 & $\begin{array}{l}\text { Blue Heart; Can boys wear } \\
\text { dresses? }\end{array}$ \\
\hline & Racismo & 1 & My afro curlyhair \\
\hline & Pré-julgamentos & 7 & $\begin{array}{l}\text { Rose's new garden; Live and } \\
\text { Learn; A Summer Day; Sweet and } \\
\text { the Mysterious Flower; Twice } \\
\text { upon a time; The three pieces; We } \\
\text { are all important }\end{array}$ \\
\hline & $\begin{array}{l}\text { Preconceitos por aparência } \\
\text { física }\end{array}$ & 5 & $\begin{array}{l}\text { The Freckle-faced girl; Do you } \\
\text { want to play with me?; } \\
\text { Unecessaur; Dirty paws }\end{array}$ \\
\hline & $\begin{array}{l}\text { Perigos contidos na repetição } \\
\text { de discursos prontos }\end{array}$ & 1 & Wireless Phone \\
\hline & $\begin{array}{l}\text { Preconceitos por deficiências } \\
\text { físicas }\end{array}$ & 2 & $\begin{array}{l}\text { First day of class (cegueira); } \\
\text { Colors and Colors (daltonismo); } \\
\text { The Language of Love (surdez) }\end{array}$ \\
\hline & $\begin{array}{l}\text { Importância do respeito à } \\
\text { diversidade }\end{array}$ & 7 & $\begin{array}{l}\text { A radical worm; The Bee and the } \\
\text { caterpillar; Gold, the precious dog; } \\
\text { Say NO to bullying; Diversity is } \\
\text { everywhere; Living in a world of } \\
\text { diversity and respect; School: a } \\
\text { place for happy (and not identical) } \\
\text { people; The school of love }\end{array}$ \\
\hline & Respeito à velhice & 2 & $\begin{array}{l}\text { Learning with Sausage, the dog; } \\
\text { Learning Respect with Grandma } \\
\text { Lucy }\end{array}$ \\
\hline
\end{tabular}

Fonte: Elaborado pela autora.

Foi pedido que para a apresentação dos livros a L2 fosse utilizada. Os alunos deveriam justificar a escolha do subtema e resumir sua história para a turma. Como uma variação, o grupo poderia encenar o enredo, se assim o desejasse. Os alunos que tinham maior conhecimento da língua foram encorajados a trabalhar de forma colaborativa com seus pares, auxiliando-os com o texto para a apresentação e com a pronúncia. Na visão 
de Torma (2011, p. 4), o trabalho colaborativo demonstra ser uma estratégia bastante significativa para que seja possível promover uma construção do conhecimento como prática para o exercício da cidadania em uma perspectiva global, já que "o conhecimento humano é construído tanto pela prática social como na prática social”. Um relato de uma participante ilustra essa percepção:

Falar em inglês não foi uma parte que foi um problema, mas eu sempre fico ansiosa com apresentações, com o coração disparado e tudo mais. Eu não gosto. Mas foi divertido, e como eu tinha ajudadas minhas amigas com a parte delas, foi muito bom vê-las falando muito bem em inglês.

Uma das alunas que fazia estágio na escola onde eu atuava como docente da educação básica, autora do livro My Afro Curly Hair, levou sua obra para ser trabalhada no estágio com os alunos do sexto ano sob a minha supervisão. A história retratava sua própria vivência: a de uma menina negra que, quando criança, tinha vergonha de seus cabelos crespos, "bem enroladinhos", como definiu ao contar a história aos alunos. Ao trabalhar a história em sala, a autora deu vida à personagem e encenou diversas partes do enredo, além de dialogar com os alunos sobre racismo e diferenças físicas, que são superficiais e que, em suas palavras, "em nada afetam a beleza de uma criança". Foi um momento de aprendizagem para os alunos e para a própria estagiária, que relatou sentirse bem ao poder trabalhar e discutir com os alunos sobre pontos que a fizeram se sentir frágil durante sua infância. Esse foi provavelmente um momento de crescimento profissional da estagiária e de grande desenvolvimento e reflexão dos alunos que participaram da aula.

Um dos livros, Twice Upon a Time, foi entregue em versão impressa, bem como em versão eletrônica: um $e$-book com linguagem simples, bastante colorido e atrativo. $\mathrm{O}$ aluno que o escreveu permitiu a divulgação do seu trabalho para que os professores da rede pública tenham a oportunidade de projetar o livro e trabalhar o conteúdo com a utilização de tecnologias, como o data-show ou o próprio smartphone dos alunos. Prensky (2001) aponta que diversas discordâncias entre docentes e discentes aparecem nas salas de aula, uma vez que os alunos podem achar a dinâmica e metodologia das aulas ultrapassadas e maçantes. Com a dispersão, podem surgir conversas paralelas, desinteresse e outros problemas. Acredita-se que por meio do trabalho com a utilização da projeção do $e$-book, na visão do aluno-autor da obra, a aula pode tornar-se mais interessante, o que justifica sua escolha pelo formato digital de seu livro. 
Outro professor em formação, autor de My first Day of Class (Figura 1), criou sua obra de forma que ela possa ser trabalhada com alunos cegos e não-cegos; ou seja, em uma página há o texto em inglês e, no outro, caracteres em braille. No entanto, ele não conseguiu, na cidade, em um primeiro momento, uma gráfica que imprimisse os caracteres em braille. Ficou combinado, então, que ele entregaria a versão simples e, no semestre seguinte, após a impressão, o livro seria doado a alguma escola que já tivesse alunos com alguma deficiência visual. Além da utilização do braille, o autor colocou código de leitura QR para que o aluno pudesse ter acesso a algumas músicas, a que o autor se referiu na obra, por meio de aplicativos instalados em seu celular que permitissem a leitura de tal código.

O autor utilizou, ainda, como ilustração, pinturas feitas por Andrea Wan, artista de Hong Kong, que retrata a cegueira em muitas de suas obras, que contribuíram para deixar o livro atrativo também para não-cegos. Desse modo, ao utilizar este material, é possível trabalhar com os alunos em uma perspectiva que visa ao desenvolvimento de letramentos múltiplos, como o letramento digital, uma vez que o autor buscou utilizar novas tecnologias, como o $\mathrm{QR}$ code. O livro oferece, portanto, aos professores que estiverem dispostos a fazê-lo, a possibilidade de se trabalhar sob a perspectiva crítica, já que o autor fez da obra uma fonte para momentos de reflexão e desenvolvimento da consciência sobre os portadores de necessidades especiais

Figura 1. Livro: My first day of class $^{3}$

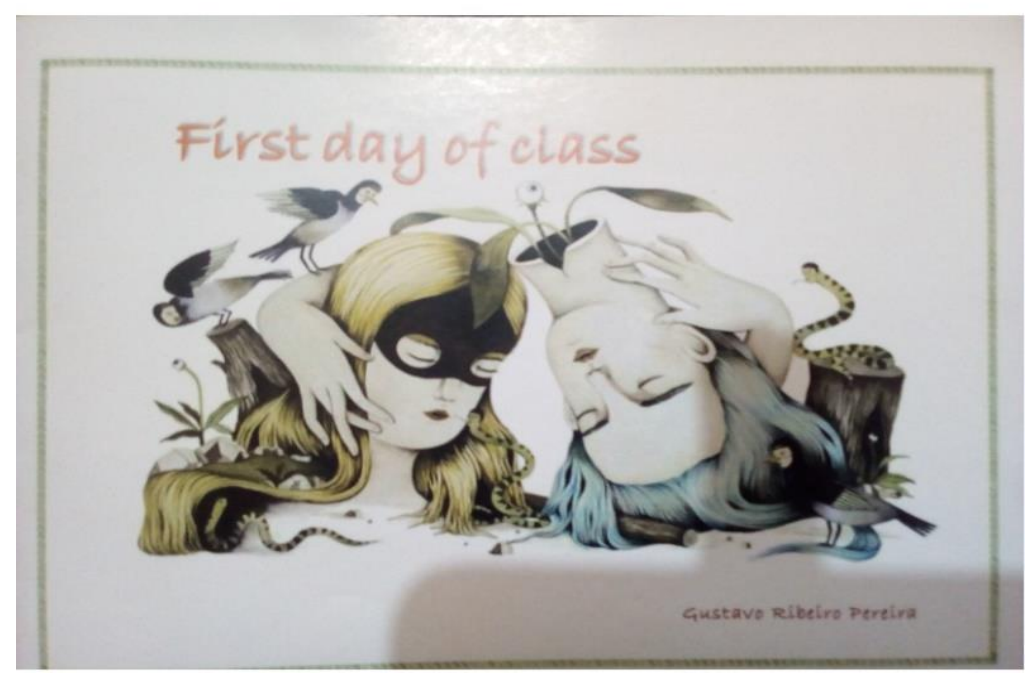

Fonte: Da autora.

\footnotetext{
${ }^{3}$ Livro elaborado pelo professor em formação do curso de Licenciatura em Letras Gustavo Ribeiro Pereira.
} 
Santos (2000) pondera que, além de crianças portadoras de deficiências, há de se pensar nas diversas outras que enfrentam dificuldades temporárias ou permanentes e que se encontram na escola. Há crianças que, por motivos diversos, repetem continuamente os anos escolares, além das que são forçadas a trabalhar. Há também aquelas que vivem nas ruas, na zona rural e outras que moram distantes de quaisquer escolas. Algumas vivem em situações de extrema pobreza, enquanto outras sofrem de abusos contínuos, ou simplesmente estão fora da escola, por outros motivos não explicitados aqui. Para o ensino de LI visando à justiça social (FREIRE, 2004), é importante buscar situações em que essas crianças sejam incluídas de forma que seja possível diminuir as barreiras no processo de ensino e aprendizagem.

Outros três grupos fizeram a impressão do livro em preto e branco para que os alunos que o utilizarem futuramente possam colorir as imagens e, assim, interagir com a obra. Eles deram permissão para que os professores reproduzam o livro, de forma que todos os estudantes tenham acesso ao conteúdo e coloram livremente as gravuras, como pode ser visto na Figura 2.

Figura 2. Livro: Gold, the precious $\operatorname{dog}^{4}$

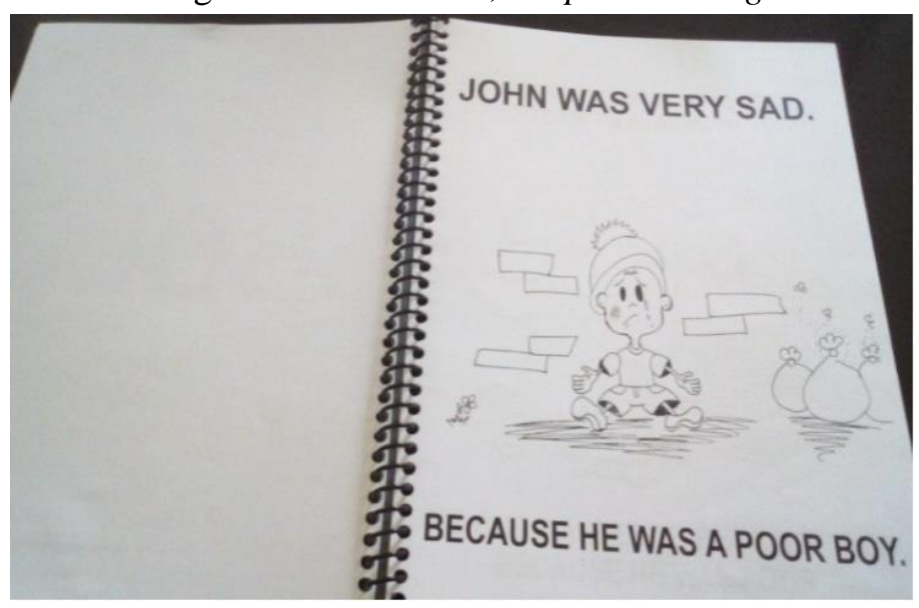

Fonte: Da autora.

Um outro grupo fez a capa de dobraduras, de forma que a personagem fica em pé ao puxar uma cordinha, como pode ser visto na Figura 3. O resultado do trabalho foi um livro colorido, bem escrito e muito atrativo para crianças e adolescentes.

\footnotetext{
4 Livro elaborado pelos professores em formação do curso de Licenciatura em Letras: Alexandre Gregório, Juliane Gregório e Victória Cerezo. Ilustrado por Tobias Bernardes.
} 


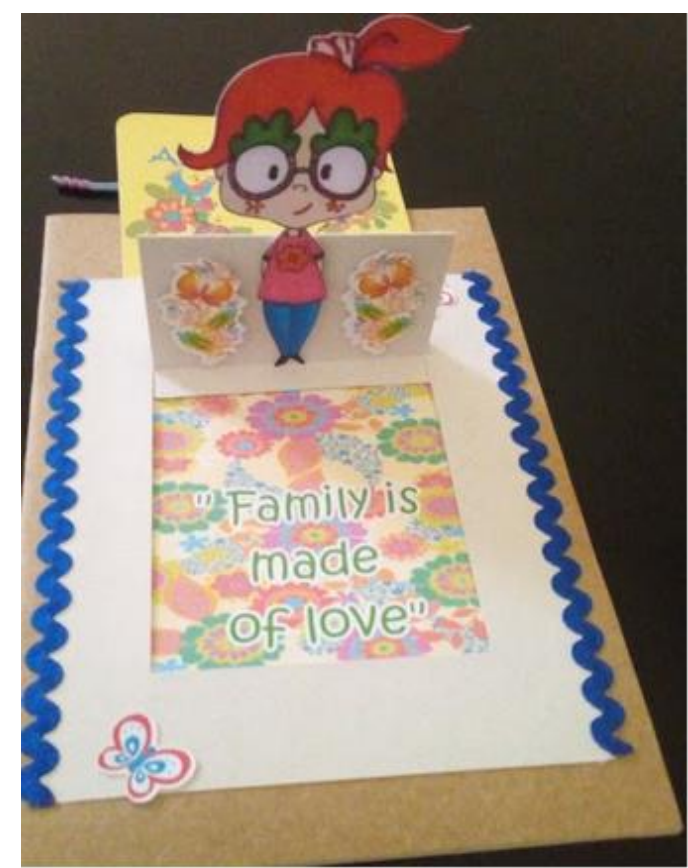

Fonte: Da autora.

Grande parte dos livros já foi entregue a três escolas públicas da cidade. Outros, no entanto, apresentaram alguns erros e precisaram ser reimpressos; por esse motivo, ainda não foram entregues. A entrega dos últimos livros será realizada ainda no semestre vigente.

É importante salientar que as percepções aqui relatadas foram coletadas durante todo o desenvolvimento da atividade por meio de anotações em diários de campo que foram feitas ora nos momentos de observação dos grupos, ora quando havia relatos informais, ou ainda por meio de mensagens via WhatsApp.

As impressões gerais colhidas no decorrer do projeto são de que os alunos se engajaram desde o início, quando souberam que os seus livros estariam nas prateleiras das escolas públicas onde poderão vir a trabalhar futuramente. Tratou-se de um trabalho colaborativo, em que, juntos, os alunos utilizaram seus diversos saberes para a confecção de um trabalho não apenas acadêmico, mas social, ao criar textos que possibilitam e encorajam, por meio de seu conteúdo, reflexões e discussões sociais nas aulas de inglês, desde que o professor que os utilizar esteja disposto a fazê-lo.

\section{CONSIDERAÇÕES FINAIS}

\footnotetext{
${ }^{5}$ Livro elaborado pelos professores em formação do curso de Licenciatura em Letras: Matheus Silveira e Raphaela Portes.
} 
Este artigo foi escrito com a finalidade de discutir o papel da escola e dos educadores frente a um novo comportamento social dos estudantes em face de uma comunicação em rede instantânea, que conecta povos de todas as etnias, cores e credos ao redor do mundo por meio da apresentação de uma proposta didática aplicada a alunos do curso de Licenciatura em Letras. Diante disso, alunos do curso de Letras foram levados a desenvolver livros que possibilitassem um trabalho de leitura considerando uma perspectiva crítica de ensino, visando a uma educação transformadora.

É importante salientar que o foco deste trabalho foi fazer com que os alunos do curso de Letras pudessem vivenciar um trabalho sob o viés da pedagogia crítica ao serem levados a pensar em possibilidades de fomentar discussões relevantes nas escolas; no entanto, não é possível definir se os livros, de fato, serão utilizados pelos professores. E mesmo que sejam utilizados, não é possível saber de que forma o trabalho será conduzido. O que se sabe é que cada livro foi cuidadosamente elaborado com temas socialmente pertinentes, que possibilitam amplas discussões, caso os professores optem por fazê-lo.

O ensino sob o viés da pedagogia crítica permite que a educação extrapole os muros institucionais, ao instigar os alunos a partir da teoria para a ação em favor de uma sociedade mais justa e mais humanizada, o que foi perceptível na proposta aqui relatada. Os alunos de Letras puderam repensar o ensino de LI determinando pontos cruciais para educar cidadãos sobre globalização, cidadania e cultura, conforme sugeriu Brydon (2009) ao longo do artigo.

No entanto, sabe-se que implementar metodologias de ensino que visem ao letramento crítico e um discurso de empoderamento que lute contra as injustiças sociais não é uma solução rápida (VETTER, 2008), mas é preciso investir na formação de professores para que eles levem novas propostas de ensino para suas aulas, conforme estabelece Zeichner (2010). Caso contrário, os alunos continuarão a acreditar e a reproduzir um discurso dominante que objetiva calar vozes e subjugar cidadãos por meio de práticas discriminatórias. Desse modo, conclui-se que as discussões sobre o ensino transformador devem fazer parte do cotidiano da sala de aula dos alunos do curso de Letras para que eles se recordem sempre de que a escola é o local mais adequado, por excelência, para desenvolver o potencial transformador da educação (MATTOS, 2011).

\section{REFERÊNCIAS}

ADAMS, M. Teaching for diversity and social justice. Routledge, 2016. 
BRASIL. Instituto Nacional de Estudos e Pesquisas Educacionais Anísio Teixeira. Censo Escolar de 2018: resumo técnico, 2018.

BRYDON, D. Globalization and higher education: working toward cognitive justice. São Paulo: DLM/USP, 22 jan. 2009. Conferência.

CHIARINI, A. M. Língua e cultura na globalização: algumas implicações na sala de aula de língua estrangeira. Congresso da associação dos professores de língua inglesa do estado de Minas Gerais \& Encontro e professores de línguas estrangeiras do CEFET-MG, 2001, Belo Horizonte. Anais [...] APLIEMGE/CEFET-MG, 2001, p. 7279.

COPE, B.; KALANTZIS, M. Language education and multiliteracies. In: HORNBERGER, N. H. (Org.). Encyclopedia of language and education, v. 1. New York: Springer, 2008. p. 195-211.

FREIRE, P. Pedagogia do Oprimido. 23ª ed. Rio de Janeiro: Paz e Terra, 2004.

FREIRE, P. Professora sim; tia, não: Cartas a quem ousa ensinar. 23 a ed. Rio de Janeiro: Civilização Brasileira, 2012.

GIROUX, H. Border Pedagogy and the Politics of Modernism/Postmodernism. Journal of Architectural Education. 1991, p. 69-79.

KALANTZIS, M. Elements of a science education. The Australian Educational researcher, v. 33, n. 2, 2006.

LANKSHEAR, C.; KNOBEL, M. Critical Literacy and New Technologies. Symposium paper, American Educational Research Association Annual Conference. San Diego, 1998, p. 13-17.

MATTOS, A. M. A. O ensino de Inglês como língua estrangeira na escola pública: novos letramentos, globalização e cidadania. 2011. Tese (Doutorado em Estudos Linguísticos e Literários em Inglês). Faculdade de Filosofia, Letras e Ciências Humanas, Universidade de São Paulo, São Paulo, 2011.

MATTOS, A. M. A. Education for Citizenship: Introducing Critical Literacy in the EFL Classroom. In: GILLIES, R. M. (Ed.). Pedagogy: new developments in the learning sciences. New York: Nova Publishers, 2012, p. 191-212.

MATTOS, A. M. A. New Literacies: Current Perspectives on Teaching English as a Foreign Language. In: Adrienne Murphy. (Org.). New Developments in Foreign Language Learning. New York: Nova Science Publishers, 2016, p. 175-194.

MENEZES DE SOUZA, L. M. T.; MONTE-MÓR, W. M. Orientações curriculares para o ensino médio: linguagens, códigos e suas tecnologias - conhecimentos de línguas estrangeiras. Brasília: Ministério da Educação/Secretaria de Educação Básica, 2006. 
MONTE-MOR, W. M. Crítica e Letramentos Críticos: reflexões preliminares. In: ROCHA, C. H.; MACIEL, R. F. (Org.). Língua estrangeira e formação cidadã: por entre discursos e práticas. Campinas: Pontes Editores, v. 01, 2013, p. 31-59.

MORAES BEZERRA, I. C. R.; SANTOS, M. R. Língua inglesa para crianças e um projeto de iniciação à docência: formação inicial exploratória. Revista Aproximando, v. 04, n. 05, 2018.

PENNYCOOK, A. The Cultural Politics of English as an International Language. London: Longman, 1994.

PRENSKY, M. Digital Natives, Digital Immigrants. On the Horizon, v. 9, n. 5, 2001.

RABIN, J. S. Survival connections and social change. In: JOHNSON, R. G. (Ed.). A twenty-first century approach to teaching social justice: educating for both advocacy and action. New York: Peter Lang Publishing, 2009, p. 167-190.

SANTOS, M. P. A Inclusão da Criança com Necessidades Educacionais Especiais. Caderno do fórum permanente de educação e saúde. MEC/Instituto Philippe Pinel, 2000, p. 56-62.

SANTOS, B. M. Justiça Social e Letramento Crítico: reflexões sobre o ensino de inglês como língua adicional no projeto Casas de Cultura no campus da UFAL. Dissertação (Mestrado em Letras e Linguística). Universidade Federal de Alagoas, Maceió, 2018.

THE NEW LONDON GROUP. A pedagogy of multiliteracies: Designing social futures. Harvard educational review, 1996, p. 60-93.

TORMA, K. R. P. O trabalho colaborativo para a aprendizagem de inglês como língua adicional com portadores de necessidades especiais. Anais Eletrônicos do IX Congresso Brasileiro de Linguística Aplicada, 2011.

VAN LIER, L. From Input to Affordance: Social Interactive Learning from an Ecological Perspective. In: J. P. Lantolf (Ed.). Sociocultural Theory and Second Language Learning: Recent Advances, p. 245-259. Oxford: OUP., 2000.

VETTER, D. Towards a critical stance: citizenship education in the classroom. In: O'SUlliVAN, M.; PASHBY, K. (Eds.). Citizenship education in the era of globalization: Canadian Perspectives. Rotterdam: Sense Publishers, 2008, p. 105-111.

YAMAKAWA, I. A. Ensino de Língua Inglesa, O papel do texto literário na formação do leitor. In: Anais do I Encontro de diálogos literários: um olhar para além das fronteiras/Mônica Luiza Socio Fernandes; [et al...] Campo Mourão. p. 179, 2013.

ZEICHNER, K. Repensando as conexões entre a formação na universidade e as experiências de campo na formação de professores em faculdades e universidades. Revista Educação, Santa Maria, v. 35, n. 3, p. 479-504. set./dez. 2010. 


\title{
APÊNDICE I
}

\author{
Plano de Aula \\ Componente Curricular: Língua Inglesa II, IV e VI \\ Docente: Míriam Rabelo Gontijo
}

Data: Todas as sextas-feiras de 19/10/2018 a 07/12/2018

Horário: 19 às $21 \mathrm{~h}$

Tempo previsto: 5 encontros de 2 horas cada

Público a qual se destina: Alunos do $2^{\circ}, 4^{\circ}$ e $6^{\circ}$ períodos do curso de Letras

Tema: Ensino de inglês como língua estrangeira para promoção da justiça social visando a um ensino transformador.

\section{Objetivos:}

- Apresentar e discutir os conceitos de pedagogia crítica, letramento crítico e ensino transformador de L2 por meio de textos indicados na bibliografia deste documento;

- Apresentar livros de literatura infantil para que os alunos percebam detalhes sobre sua constituição;

- Instigar os alunos para que elaborem uma história, em língua inglesa, que possa ser transformada em um livro infantil;

- Doar os livros para as bibliotecas das escolas públicas.

\section{Recursos Didáticos:}

- Projetor multimídia;

- Canetas, pincéis e lápis de colorir (para as ilustrações);

- Dicionários;

- Acesso à Internet para pesquisas diversas.

\section{Procedimentos Metodológicos:}

- Exposição oral do professor;

- Discutir as questões levantadas pelos discentes na problematização e na contextualização da aula;

- Divisão da sala em grupos de trabalhos para criação da obra;

- Exposição oral dos alunos.

Sequência Didática:

$1^{\circ}$ Momento - (19 e 26/10): apresentação e introdução da teoria: Pedagogia crítica (PENNYCOOK, 1994); multiletramentos (THE NEW LONDON GROUP, 1996) e ensino transformador de inglês como língua estrangeira (KALANTZIS, 2006; COPE; KALANTZIS, 2008).

- Os alunos serão convidados a ler os textos e debatê-los em sala na tentativa de relacionar os conteúdos abordados na teoria com a realidade dos discentes e da sala de aula, em especial das escolas públicas. Serão discutidos 2 textos por encontro.

$2^{\circ}$ Momento (09/11): Apresentação de livros infantis diversos para reconhecimento do gênero e contação de história.

- Neste dia os alunos começarão a elaborar o livro infantil de sua própria autoria. Para motivá-los, será contada a história The Lion Who Wouldn't Try, dos autores André Kieswetter, Liza Esterhuyse, Nick Mulgrew e Tarryn-Anne Anderson. Na sequência, mostrarei diversos livros infantis à turma e deixarei que eles percebam as características do gênero e, dentre eles, quais aspectos são 
obrigatórios e quais são opcionais. Será feito um brainstorming para fomentar a discussão sobre as percepções quanto à caracterização do gênero.

- Ainda neste dia será selecionada a linha temática dos livros.

$3^{\circ}$ Momento (16, 23 e 30/11): Desenvolvimento do livro

- Os livros serão criados parcialmente em sala de aula. Na primeira aula deste momento (16/11), os alunos deverão selecionar o subtema a ser abordado, criar as personagens e o roteiro.

- Na segunda aula (23/11), os alunos deverão escrever a história, de forma colaborativa, com o auxílio da professora quando necessário e dos recursos digitais e impressos a seu dispor, como dicionários físicos, aplicativos de celulares e dicionários virtuais.

- Para que haja êxito na atividade proposta, os alunos deverão continuar a criação em suas casas e poderão se comunicar com a professora via WhatsApp sempre que necessário.

- No dia 30/11, os livros deverão estar em processo de finalização. A docente, por escala, atenderá os grupos para discussão e correção de aspectos linguísticos do texto.

$4^{\mathbf{0}}$ Momento (07/12): avaliação e fechamento da atividade.

- Apresentação das criações para o restante da turma;

- Entrega do livro.

\section{Procedimento de avaliação da aprendizagem:}

- Observação do envolvimento discente durante o processo de desenvolvimento do livro;

- Entrega da obra elaborada por cada grupo. Todos os livros devem ser apresentados à turma antes da doação.

- Avaliação oral da apresentação dos livros. A apresentação deve ser em L2 e deve conter: a) apresentação dos autores; b) a motivação e justificativa para a escolha do sub-tema; c) o resumo (ou leitura) do livro. Como variação, o grupo poderá encenar a história.

\section{Referências:}

COPE, B.; KALANTZIS, M. Language education and multiliteracies. In:

HORNBERGER, N. H. (Org.). Encyclopedia of language and education, v. 1. New York: Springer, 2008. p. 195-211.

FREIRE, P. Pedagogia do Oprimido. 23 $3^{\text {a }}$ ed. Rio de Janeiro: Paz e Terra, 2004.

KALANTZIS, M. Elements of a science education. The Australian Educational

researcher, v. 33, n. 2, 2006.

PENNYCOOK, A. The Cultural Politics of English as an International Language.

London: Longman, 1994. 